\title{
Dynamic magnification factors for tree blow-down by powder snow avalanche air blasts
}

\author{
Perry Bartelt ${ }^{1}$, Peter Bebi ${ }^{1}$, Thomas Feistl ${ }^{2}$, Othmar Buser ${ }^{2}$, and Andrin Caviezel ${ }^{1}$ \\ ${ }^{1}$ WSL Institute for Snow and Avalanche Research SLF, Flüelastrasse 11, 7260 Davos Dorf, Switzerland \\ ${ }^{2}$ Lawinenwarnzentrale im bayerischen Landesamt für Umwelt, Hessstrasse 128, 80797 Munich, Germany
}

Correspondence: Perry Bartelt (bartelt@slf.ch)

Received: 16 June 2017 - Discussion started: 7 July 2017

Revised: 26 January 2018 - Accepted: 1 February 2018 - Published: 7 March 2018

\begin{abstract}
We study how short duration powder avalanche blasts can break and overturn tall trees. Tree blow-down is often used to back-calculate avalanche pressure and therefore constrain avalanche flow velocity and motion. We find that tall trees are susceptible to avalanche air blasts because the duration of the air blast is near to the period of vibration of tall trees, both in bending and root-plate overturning. Dynamic magnification factors for bending and overturning failures should therefore be considered when back-calculating avalanche impact pressures.
\end{abstract}

\section{Introduction}

In this paper we develop a simple method to determine the dynamic response of trees to impulsive loads. This is an important problem in natural hazards engineering where historical evidence of forest destruction or tree breakage is often used to evaluate the potential avalanche hazard. Any indication of forest damage is particularly valuable to avalanche engineers because it helps define the destructive reach of an extreme and infrequent event. Fallen tree stems delineate the spatial extent of an avalanche and create a natural vector field indicating the primary flow direction of the movement (Fig. 1). The age of the destroyed trees can be additionally used to link the historical observations to the avalanche return period (Reardon et al., 2008; Schläppy et al., 2014; Gadek et al., 2017). In many cases observations of forest destruction are the only data the engineer has to quantify avalanche danger.
The problem with using evidence of tree destruction for avalanche mitigation planning is that a simple relationship between avalanche impact pressure and tree failure is difficult to establish. Tree-breaking depends on both the avalanche loading and tree strength. Trees fall if the bending stress exerted by the avalanche exceeds the bending strength of the tree stem (Johnson, 1987; Mattheck and Breloer, 1994; Peltola et al., 1997, 1999) or if the applied torque overcomes the strength of the root-soil plate, leading to uprooting and overturning (Coutts, 1983; Mattheck and Breloer, 1994; Jonsson et al., 2006). Both mechanisms depend on the local flow height of the avalanche. Recent observations by Feistl et al. (2015b) suggest that the magnitude of the avalanche impact pressure is strongly related to the avalanche flow regime. Although long recognised that dense flowing avalanches can easily break, overturn and uproot trees (Bartelt and Stöckli, 2001; Feistl et al., 2015a), tree destruction by powder avalanche air blasts has received less attention. A mechanical understanding of how trees are blowndown by powder avalanche blasts would allow engineers to quantify powder avalanche pressures from case studies and historical records.

Here we develop a mechanical model to predict the natural frequency of trees subject to full-height air-blasts of powder snow or ice avalanches. We assume two deformation modes: stem bending and root-plate overturning, see Figs. 2 and 3. The ratio of the natural tree frequency to the frequency of the avalanche air-blast defines the dynamic magnification factor $D$ (Clough and Penzien, 1975). This value is used to magnify the non-impulsive loadings $D>1$ to account for the increase in stress under an impulsive load. The eigenfrequency of the tree is a function of the tree height, stiffness and mass 


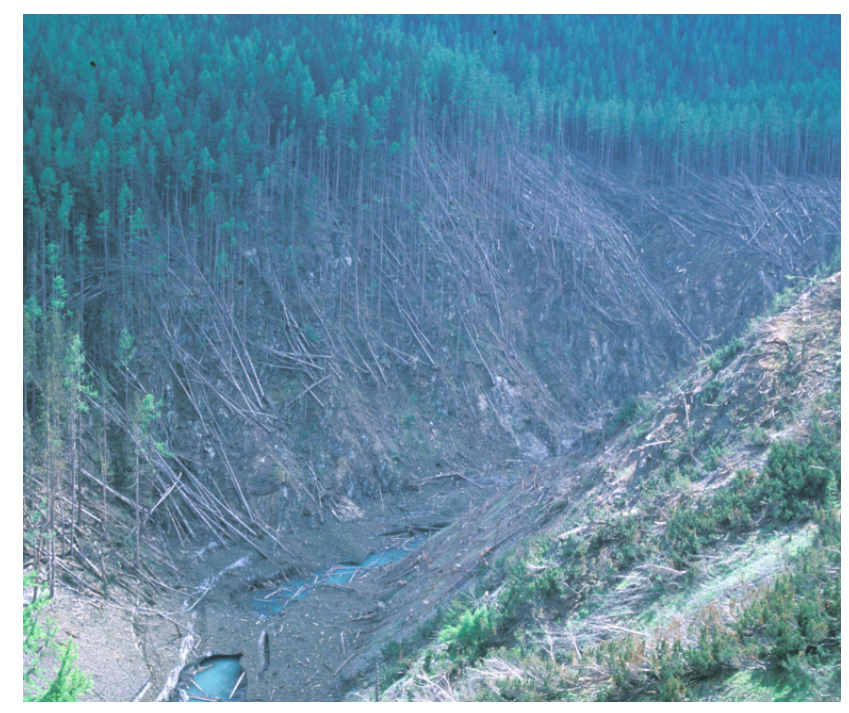

Figure 1. Tree breakage caused by the air blast of a powder avalanche, Zernez, Switzerland, 1999. The trees failed through a combination of bending and root-plate overturning. Photograph: Peter Bebi, SLF.

distribution between the stem and branches. It therefore depends on forest age and tree species. We show that dynamic magnification factors for fully grown trees are large indicating that mature forests are especially vulnerable to powder snow avalanches. As we shall see, an error of up to $25 \%$ can be made when back-calculating avalanche velocities. For example, an avalanche travelling at $35 \mathrm{~m} \mathrm{~s}^{-1}$ exerts the same pressure as an avalanche travelling at $50 \mathrm{~m} \mathrm{~s}^{-1}$ if the impulsive nature of the loading is considered. These are significant differences in hazard mitigation studies.

\section{Tree response to impulsive loading}

Measurements on real avalanches reveal that the air-blast is intermittent and of short duration, lasting only a few seconds (Grigoryan et al., 1982; Sukhanov and Kholobaeva, 1982; Sukhanov, 1982). When a powder avalanche hits a forest the ice-dust cloud is typically moving at velocities in excess of $50 \mathrm{~m} \mathrm{~s}^{-1}$ (similar to extreme wind gusts). The height of the cloud is equal, if not larger, than the height of the tree, i.e. $H>20 \mathrm{~m}$. The pressure blast thus acts over the entire width and height of the tree, producing large bending moments in the stem and straining the root base plate. The impulsive character of the powder avalanche air-blast, however, magnifies the static stress state (Clough and Penzien, 1975). The fallen tree stems often point in the direction of the flow, indicating that the trees had little time to sway and react to blast and that the inertial effects are of considerable importance.

To calculate the dynamic magnification factor $D$ we first make three simplifying assumptions. Firstly, the air blast can be expressed as a sine wave impulse with duration time $t_{0}$. Moreover,

$F(t)=F_{0} \sin \bar{\omega} t$,

where $\bar{\omega}$ is the circular frequency of the loading $\bar{\omega}=\pi / t_{0}$. The magnitude of the force $F_{0}$ is as follows:

$F_{0}=p_{0} A=\frac{1}{2} c_{\mathrm{d}} \rho U_{\max }^{2} A$,

where $p_{0}$ is the amplitude of the avalanche pressure given by the density of the powder cloud $\rho$, the form drag coefficient of the tree $c_{\mathrm{d}}$ and the maximum velocity of the blast $U_{\max }$ (Bozhinskiy and Losev, 1998; Feistl et al., 2015a). The tree area over which the blast acts is denoted $A$, typically given by the tree height $H$ and effective tree width $W$. Thus, if the cloud density and velocity are known as well as the tree geometry, the magnitude of the applied blast force $F_{0}$ is given.

After the loading time $t_{0}$, the tree vibrates freely with natural frequency $\omega$. The natural frequency is found using the Rayleigh quotient method (Clough and Penzien, 1975), which assumes the deflected form is known (but not the magnitude of deformation). The assumption of a deflected shape reduces the tree to a single degree of freedom system. The frequency is found by equating the maximum strain energy $V_{\max }$ to the maximum kinetic energy $T_{\max }$ developed during the tree response. By calculating the strain and kinetic energy produced by the avalanche blast, we find the generalised stiffness $K$ and generalised mass $M$ of the tree:

$\omega^{2}=\frac{K}{M}$.

The natural frequency for two different deformation modes, stem bending $\omega_{\mathrm{sb}}$ and root-overturning $\omega_{\text {ro }}$ will be determined in the next sections.

In both cases the total tree height is $H$. Tree mass is divided into two parts: the stem mass $m_{\mathrm{S}}$ (a mass per unit length of the tree $\mathrm{kg} \mathrm{m}^{-1}$ ) and the total mass of the branches $M_{\mathrm{b}}(\mathrm{kg})$. The branch mass, including the mass of needles, is lumped at the tree centre-of-mass. The mass $M_{\mathrm{b}}$ can include the mass of snow held by the branches and thus, like the tree elasticity, have some seasonal variation. As we assume a constant stem diameter $d$ the stem mass per unit length is,

$m_{\mathrm{s}}=\rho_{\mathrm{t}} A_{\mathrm{t}}$

with

$A_{\mathrm{t}}=\frac{\pi}{4} d^{2}$.

The density of the stem wood is $\rho_{\mathrm{t}}$. For both the bending and overturning cases, the concentrated load $F_{0}$ acts at the tree centre-of-mass, which is located a distance $a$ from the ground (see Figs. 2 and 3).

Finally, the third assumption, the maximum response of the tree, will be reached before the damping forces can absorb the energy of the air blast. Only the undamped response to a short duration blast is considered. 


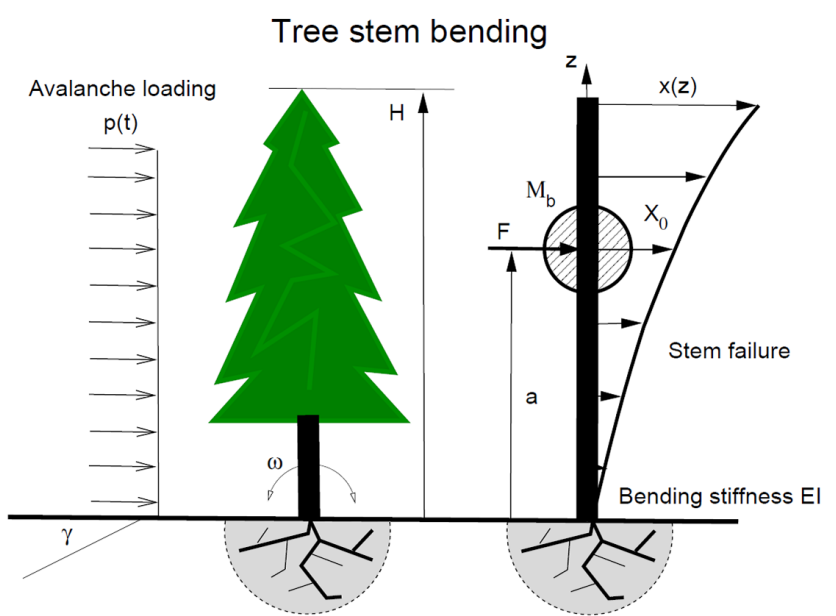

Figure 2. A tree of height $H$ breaks in bending. The avalanche exerts a loading $p(t)$ of known (but short) duration. The load acts in the centre-of-mass of the tree located a distance $a$ from the ground. The mass of the linear distributed mass of the tree stem is $m_{\mathrm{t}}$ and the lumped mass of the branches is $M_{\mathrm{b}}$. Tree deformation is given by the non-linear distribution $x(z)$.

\subsection{Eigenfrequency: tree bending mode}

For the case of tree bending, the deformation $x(z)$ at height $z$ is given by (see Fig. 2):

$x_{1}(z)=X_{0} \psi_{1}(z)=\frac{F a^{2}(3 H-a)}{3 E I}\left[\frac{3 a z^{2}-z^{3}}{2 a^{2}(3 H-a)}\right]$

$$
\text { for } z \leq a
$$

and

$$
\begin{aligned}
x_{2}(z)= & X_{0} \psi_{2}(z)=\frac{F a^{2}(3 H-a)}{3 E I}\left[\frac{3 z a^{2}-a^{3}}{2 a^{2}(3 H-a)}\right] \\
& \text { for } z>a,
\end{aligned}
$$

where $E$ is the modulus of elasticity of the tree stem and $I$ is the moment of inertia. The functions $\psi_{1}(z)$ and $\psi_{2}(z)$ represent interpolation functions for the deformation field. These equations for lateral tree deformation are found by assuming the tree is a statically determinate cantilever-type structure fixed at the base to the ground (see Fig. 2 and Clough and Penzien, 1975). The largest bending moment in the tree is found at the tree base, $z=0$. The quantity $X_{0}$ is the static deformation under the blast load $F$,

$X_{0}=\frac{F a^{2}(3 H-a)}{3 E I}$.

The moment of inertia is taken for circular stem sections,

$I=\frac{\pi d^{4}}{64}$.

The maximum potential strain energy in bending is as follows (Clough and Penzien, 1975)

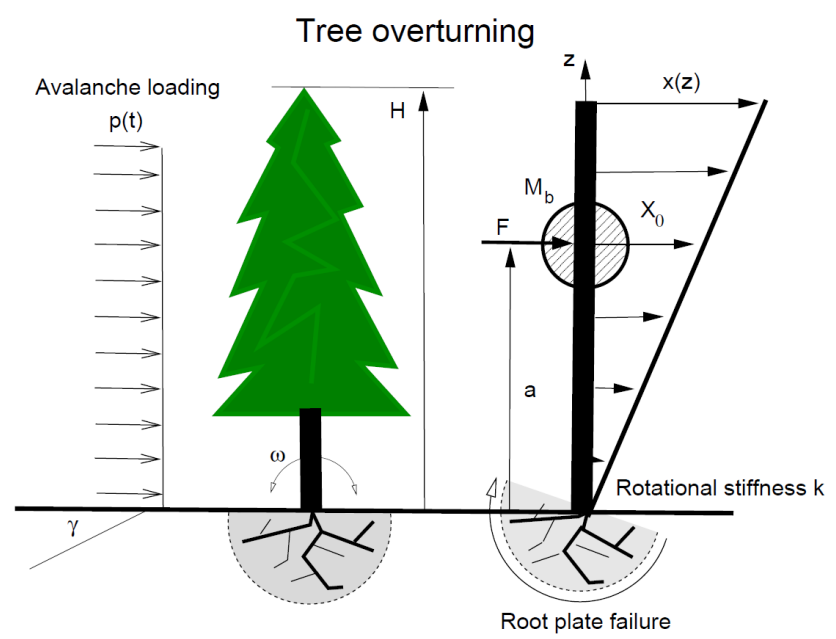

Figure 3. A tree of height $H$ breaks by overturning at the root-plate. The avalanche exerts a loading $p(t)$ of known (but short) duration. The load acts in the centre-of-mass of the tree located a distance $a$ from the ground. The mass of the linear distributed mass of the tree stem is $m_{\mathrm{t}}$ and the lumped mass of the branches is $M_{\mathrm{b}}$. Tree deformation is given by the linear distribution $v(z)$.

$V_{\max }=\frac{1}{2} X_{0}^{2} \int_{0}^{a} E I(z) x_{1}^{2}(z) \mathrm{d} z=\frac{1}{2} \frac{3 E I}{a^{2}(3 H-a)} X_{0}^{2}$.

In the bending case, the tree is firmly rooted in the ground and strain energy is stored in the tree stem between the ground and the point of load application $z=a$. The tree stem above $z>a$ is stress free, swaying back and forth as a rigid body. The maximum kinetic energy $T_{\max }$ is composed of two parts containing the stem energy $T_{\max }^{\mathrm{s}}$ and the branch energy $T_{\max }^{\mathrm{b}}$ of the tree, $T_{\max }=T_{\max }^{\mathrm{s}}+T_{\max }^{\mathrm{b}}$ (Clough and Penzien, 1975):

$$
\begin{aligned}
T_{\max }^{\mathrm{s}} & =\frac{\omega_{\mathrm{sb}}^{2}}{2} \int_{0}^{a} m_{\mathrm{s}} x_{1}^{2}(z) \mathrm{d} z+\frac{\omega_{\mathrm{sb}}^{2}}{2} \int_{a}^{H} m_{\mathrm{s}} x_{2}^{2}(z) \mathrm{d} z \\
& =\frac{1}{280} m_{\mathrm{s}} \frac{\left[105 H^{3}-105 a H^{2}+35 H a^{2}-2 a^{3}\right]}{(3 H-a)^{2}} X_{0}^{2},
\end{aligned}
$$

and

$$
T_{\max }^{\mathrm{b}}=\frac{M_{\mathrm{b}} \omega_{\mathrm{sb}}^{2}}{2} x_{1}^{2}(z=a)=\frac{M_{\mathrm{b}} \omega_{\mathrm{sb}}^{2}}{2} X_{0}^{2} \frac{a^{2}}{(3 H-a)^{2}} .
$$

The eigenfrequency $\omega_{\mathrm{sb}}^{2}$ is found by equating $T_{\max }=V_{\max }$ :

$$
\omega_{\mathrm{sb}}^{2}=\frac{420 E I(3 H-a)}{a^{2} m_{\mathrm{s}}\left[105 H^{3}-105 a H^{2}+35 H a^{2}-2 a^{3}+\frac{140 a^{2} M_{\mathrm{b}}}{m_{\mathrm{t}}}\right]} .
$$




\subsection{Eigenfrequency: tree overturning mode}

For the tree overturning case,

$x(z)=X_{0} \psi(z)=\frac{F a H}{k}\left[\frac{z}{H}\right]$,

where $k$ is the overturning stiffness of the root-plate. This equation is found by assuming the lateral tree deformation is governed by a torsional spring, representing the stiffness of the root-plate (see Fig. 3 and Chajes, 1974). The maximum potential strain energy (overturning) is then

$V_{\max }=\frac{1}{2} F X_{0}=\frac{1}{2} \frac{k}{a H} X_{0}^{2}$.

Similar to the bending case, the maximum kinetic energy is found by considering the stem and branch energies separately:

$T_{\max }^{\mathrm{s}}=\frac{\omega_{\mathrm{ro}}^{2}}{2} \int_{a}^{H} m_{\mathrm{s}} x_{1}^{2}(z) \mathrm{d} z=\frac{1}{6} m_{\mathrm{s}} \frac{a^{3}}{H^{2}} X_{0}^{2}$

and

$T_{\max }^{\mathrm{b}}=\frac{M_{\mathrm{b}} \omega_{\mathrm{ro}}^{2}}{2} x^{2}(z=a)=\frac{M_{\mathrm{b}} \omega_{\mathrm{ro}}^{2}}{2} X_{0}^{2} \frac{a^{2}}{H^{2}}$.

The eigenfrequency $\omega_{\mathrm{ro}}^{2}$ is found by equating $T_{\max }=V_{\max }$ :

$\omega_{\mathrm{ro}}^{2}=\frac{3}{\left[m_{\mathrm{s}} a+3 M_{\mathrm{b}}\right]} \frac{H k}{a^{3}}$.

\section{Dynamic magnification of avalanche blast}

The equation of motion for an undamped system subjected to a harmonic loading is as follows:

$M \ddot{x}(t)+K x(t)=F(t)=F_{0} \sin \bar{\omega} t$

which has the general solution for $0 \leq t \leq t_{0}$,

$x(t)=\frac{F_{0}}{K} \frac{1}{1-\beta^{2}}(\sin \bar{t}-\beta \sin \omega t)$

and for $t>t_{0}$ :

$x(t)=\frac{\dot{x}\left(t_{0}\right)}{\omega} \sin \bar{\omega}\left(t-t_{0}\right)-x\left(t_{0}\right) \sin \omega\left(t-t_{0}\right)$,

where $\beta=\frac{\bar{\omega}}{\omega}$ is the ratio between the frequency of the avalanche blast and eigenfrequency of the tree. The magnitude of the dynamic response therefore depends on the ratio of the load duration to the period of vibration of the tree. For the case when $\beta<1$ the maximum deformation occurs when the impulsive load is active. It can be shown (see Clough and Penzien, 1975) that the time to this peak response $t_{\max }$ is:

$\bar{\omega} t_{\max }=\frac{2 \pi \beta}{\beta+1}$,
Table 1. Numerical values for the mass distribution of spruce for different tree heights. Table is constructed from data contained in Indermühle (1978), Kalberer (2006) and Kramer (1988). The stated values represent average values for spruce trees in alpine environments. Values are approximate and will change depending on their location in forest, slope exposition, etc. Branch mass includes needle mass, which is given in parenthesis. Intercepted snow mass is not included in the calculations.

\begin{tabular}{|c|c|c|c|c|c|}
\hline $\begin{array}{l}\text { Height } \\
H \\
\mathrm{~m}\end{array}$ & $\begin{array}{c}\text { Centre-of-mass } \\
a \\
\mathrm{~m}\end{array}$ & $\begin{array}{l}\text { Width } \\
w \\
\mathrm{~m}\end{array}$ & $\begin{array}{l}\text { Stem } \\
\text { DBH } d \\
\text { m }\end{array}$ & $\begin{array}{r}\text { Stem } \\
\text { mass } \\
m_{\mathrm{t}} \\
\mathrm{kg} \mathrm{m}^{-1}\end{array}$ & $\begin{array}{r}\text { Branch } \\
\text { mass } \\
M_{\mathrm{b}} \\
\mathrm{kg}\end{array}$ \\
\hline 3 & 1.80 & 2.0 & 0.10 & 3 & $4(2)$ \\
\hline 15 & 8.60 & 3.0 & 0.20 & 20 & $155(60)$ \\
\hline 22 & 13.9 & 3.5 & 0.30 & 30 & $310(120)$ \\
\hline 27 & 16.3 & 4.5 & 0.40 & 60 & $540(200)$ \\
\hline 35 & 21.2 & 7.0 & 0.70 & 150 & $1640(640)$ \\
\hline
\end{tabular}

which can be substituted into the general solution to find the dynamic magnification factor for a long duration impulse:

$D=\frac{1}{1-\beta^{2}}\left[\sin \bar{\omega} t_{\max }-\beta \sin \frac{\bar{\omega} t_{\max }}{\beta}\right]$.

It can likewise be shown that the maximum response for the free vibration case occurs when $\beta>1, t>t_{0}$. For this case, the dynamic magnification factor for a short duration impulse is:

$D=\frac{2 \beta}{1-\beta^{2}} \cos \frac{\pi}{2 \beta}$.

For the resonance case $\beta=1$

$D=\frac{\pi}{2}$

\section{Application}

To demonstrate how the dynamic magnification factor $D$ can be found, we consider the following problem: a powder snow avalanche enters a spruce forest with considerable speed $\left(>50 \mathrm{~m} \mathrm{~s}^{-1}\right)$ and exerts a short duration air-blast with frequency $\bar{\omega}$. The duration of the blast is on the order of a few seconds. The height of the trees is between 25 and $30 \mathrm{~m}$, which is also the height of the powder cloud. The cloud has decoupled from the avalanche core which has stopped before reaching the forest. Moreover, the only loading on the trees is the air-blast. 
Table 2. Natural frequencies in bending and overturning for spruce trees of different heights. $E=10 \mathrm{GPa}$. A reduced stem diameter $d=0.5 d_{\text {DBH }}$ produces a good agreement to measured frequencies. Mass distribution taken from Table 1 .

\begin{tabular}{lcrrr}
\hline $\begin{array}{l}\text { Height } \\
H\end{array}$ & $\begin{array}{c}\text { Centre-of-mass } \\
\mathrm{m}\end{array}$ & $\begin{array}{r}\omega_{\mathrm{sb}} \\
\mathrm{rad} \mathrm{s}^{-1}(\mathrm{~Hz})\end{array}$ & $\begin{array}{r}\omega_{\mathrm{ro}} \\
\mathrm{rad} \mathrm{s}^{-1}(\mathrm{~Hz})\end{array}$ & $\begin{array}{r}\omega_{\mathrm{ro}} \\
\mathrm{rad} \mathrm{s}^{-1}(\mathrm{~Hz}) \\
k=1000 \mathrm{kNm}\end{array}$ \\
\hline 3 & 1.80 & $18.20(2.90)$ & $104.00(16.55)$ & $328.88(52.34)$ \\
15 & 8.60 & $2.09(0.33)$ & $3.77(0.60)$ & $11.93(1.90)$ \\
22 & 13.9 & $1.45(0.23)$ & $0.52(0.24)$ & $4.82(0.76)$ \\
27 & 16.3 & $1.48(0.23)$ & $0.99(0.16)$ & $3.15(0.05)$ \\
35 & 21.0 & $1.65(0.26)$ & $0.43(0.07)$ & $1.36(0.21)$ \\
\hline
\end{tabular}

Using the measured mass values tabulated in Table 1, we set the total branch and needle mass of a single tree to be $M_{\mathrm{b}}=540 \mathrm{~kg}$. The stem mass per length is approximately $60 \mathrm{~kg} \mathrm{~m}^{-1}$ (wood density $480 \mathrm{~kg} \mathrm{~m}^{-3}$ ). The total force of the avalanche impact acts at the tree's centre-of-mass which is located $a=16.5 \mathrm{~m}$ above ground. This allows us to define the natural frequency in bending of the tree by Eq. (13), $\omega_{\mathrm{sb}}=1.48 \mathrm{rad} \mathrm{s}^{-1}(0.24 \mathrm{~Hz})$, see Table 2 . This value is in very good agreement with the measurements (see Jonsson et al., 2007). The modulus of elasticity was set to $E=10 \mathrm{GPa}$ based on experimental measurements (Haines et al., 1996). For the calculations, a tree diameter somewhat smaller than the diameter at breast height (DBH) is selected. In this case $d=0.2 \mathrm{~m}$, which is $1 / 2$ of the DBH diameter (this provides the best match to the experimental frequencies).

Consider first a duration sine impulse lasting $2.50 \mathrm{~s}$ $(\bar{\omega}=\pi / 6)$. In this case $\beta=0.699$; that is, the maximum deformation occurs during the time the load is acting. For this case, application of Eq. (23), we find $D=1.76$, a rather large magnification factor. For a shorter duration impulse lasting $1.66 \mathrm{~s}, \beta=1.27$ and from Eq. (24), we find $D=1.36$. The primary conclusion to draw from this analysis is that the natural frequency in bending of tall trees is close to the frequency of the applied avalanche air-blast. Measurements of air-blast duration times reported by Russian researchers are within this range, lasting only a few seconds (see Grigoryan et al., 1982; Sukhanov and Kholobaeva, 1982; Sukhanov, 1982).

Measurements of root plate stiffness are rare; however, values for $10-14 \mathrm{~m}$ high spruce reported in Neild and Wood (1998) vary between $k=80 \mathrm{kNm}(H=10 \mathrm{~m})$ and $k=1200 \mathrm{kNm}(H=14 \mathrm{~m})$. These values suggest a large variation in $k$ depending on growth conditions. The application of these $k$ stiffness values for spruce trees predicts natural frequencies for root-plate overturning in $\omega_{0}>2 \mathrm{~Hz}$ (Eq. 18), see Table 2. The calculated $\beta$ factors for overturning are typically $\beta<1$. This result suggests that large dynamic magnification factors can only be generated by very short duration impulses (less than $t<0.5 \mathrm{~s})$. Tall trees $(H>20 \mathrm{~m})$ with low root plate stiffness $(k \approx 100 \mathrm{kN} \mathrm{m})$ are vulnerable to powder avalanche air-blasts.

\section{Conclusions}

We draw several conclusions from our analysis. Firstly, the natural frequency of tall trees - in bending and overturning - is close to the loading frequency of powder avalanches, $\omega \approx \bar{\omega}$. Thus, tall trees are susceptible to powder avalanche blow-down. When using tree blow-down to estimate avalanche impact pressures (and therefore speed and density of the powder cloud) a dynamic magnification factor should be applied in the analysis. Moreover, powder avalanches can knock down trees with lower velocity than is presently assumed. This result is also valid for other types of tall structures, including power pylons, or buildings with long over-hanging roofs.

Secondly, both tree bending and root-plate overturning are possible tree failure modes when hit by a powder avalanche. Interestingly, the natural frequencies of tree bending and root-plate overturning are similar, when the root-plate stiffness is low $(k<100 \mathrm{kNm})$ and the tree is tall $(H>20 \mathrm{~m})$. Although there is considerable data available to constrain the value of the modulus of elasticity of wood $E$, there is less information available to constrain the root-plate stiffness. In the future, field investigations that document forest destruction should clearly separate bending and overturning failures. This would help understand the variability of tree anchorage on mountain slopes. The field examinations should also quantify the stem diameter $d$ at more than one location as this is necessary to accurately determine the bending eigenfrequency.

Finally, the fact that tall trees can be broken in bending and overturning indicates the nature of the avalanche air blast. It appears to be a high velocity, short duration pulse of flowing material (ice-dust), similar to a high-density gust of wind. It is not a compression wave travelling at the speed of sound.

Data availability. No data sets were used in this article.

Competing interests. The authors declare that they have no conflict of interest. 
Acknowledgements. This work was performed within the framework of the joint Austrian-Swiss project bDFA, a study of avalanche motion beyond the dense flow avalanche regime. We thank the Austrian Academy of Science (ÖAW) for their financial support as well as the Austrian research partners (Austrian Research Centre for Forests, Torrent and Avalanche Control and the University of Innsbruck).

\section{Edited by: Oded Katz}

Reviewed by: two anonymous referees

\section{References}

Bartelt, P. and Stöckli, V.: The influence of tree and branch fracture, overturning and debris entrainment on snow avalanche flow, Ann. Glaciol., 32, 209-216, 2001.

Bozhinskiy, A. N. and Losev, K. S.: The fundamentals of avalanche science, Mitt. Eidgenöss. Inst. Schnee- Lawinenforsch., Davos, p. 280, 1998.

Chajes, A.: Principles of Structural Stability Theory, Prentice Hall Inc, Englewood Cliffs, p. 336, 1974.

Clough, R. W. and Penzien, J.: Dynamics of Structures, McGrawHill Inc, New York, p. 634, 1975.

Coutts, M.: Root architecture and tree stability, Plant Soil, 71, 171188, 1983.

Feistl, T., Bebi, P., Christen, M., Margreth, S., Diefenbach, L., and Bartelt, P.: Forest damage and snow avalanche flow regime, Nat. Hazards Earth Syst. Sci., 15, 1275-1288, https://doi.org/10.5194/nhess-15-1275-2015, 2015a.

Feistl, T., Bebi, P., Teich, M., Bühler, Y., Christen, M., Thuro, K., and Bartelt, P.: Observations and modeling of the braking effect of forests on small and medium avalanches, J. Glaciol., 60, 124138, https://doi.org/10.3189/2014JoG13J055, 2015 b.

Gadek, B., Kaczka, R. J., Raczkowska, Z., Rojan, E., Casteller, A., and Bebi, P.: Snow avalanche activity in Zleb Zandarmerii in a time of climate change (Tatra Mts., Poland), Catena, 158, 201212, 2017.

Grigoryan, S., Urubayev, N., and Nekrasov, I.: Experimental investigation of an avalanche air blast, Data Glaciol. Stud., 44, 87-93, 1982.

Haines, D. W., Leban, J. M., and Herbe, C.: Determination of Young's modulus for spruce, fir and isotropic materials by the resonance flexure method with comparisons to static flexure and other dynamic methods, Wood Sci. Technol., 30, 253-263, 1996.

Indermühle, M. P.: Struktur, Alters- und Zuwachsuntersuchungenin einem Fichten-Plenterwald der subalpinen Stufe, in: Beiheft Nr. 60 zur Schweiz, Z. Forstwesen, Dissertaion ETHZ-Zürich, Zürich, p. 98, 1978.
Johnson, E. A.: The relative importance of snow avalanche disturbance and thinning on canopy plant populations, Ecology, 68, 43-53, 1987.

Jonsson, M. J., Foetzki, A., Kalberer, M., Lundström, T., Ammann, W., and Stöckli, V.: Root-soil rotation stiffness of norway spruce (Picea abies (L.) Karst) growing on subalpine forested slopes, Plant Soil, 285, 267-277, 2006.

Jonsson, M. J., Foetzki, A., Kalberer, M., Lundström, T., Ammann, W., and Stöckli, V.: Natural frequencies and damping ratios of Norway spruce (Picea abies (L.) Karst) growing on subalpine forested slopes, Trees, 21, 541-548, https://doi.org/10.1007/s00468-007-0147-x, 2007.

Kalberer, M.: Quantifizierung und Optimierung der Schutzwaldleistung gegenüber Steinschlag, Dissertaion Albert-LudwigsUniversität, Freiburg, 2006.

Kramer, H.: Waldwachstumslehre, Parey, Hamburg, Berlin, p. 374, 1988.

Mattheck, C. and Breloer, H.: Handbuch der Schadenskunde von Bäumen: Der Baumbruch in Mechanik und Rechtsprechung, Rombach, Freiburg im Breisgau, 1994.

Neild, S. A. and Wood, C. J.: Estimating stem and root-anchorage flexibility in trees, Tree Physiol., 19, 141-151, 1998.

Peltola, H., Nykänen, M. L., and Kellomäki, S.: Model computations on the critical combination of snow loading and windspeed for snow damage of scots pine, norway spruce and birch at stand edge, Forest Ecol. Manage., 95, 229-241, 1997.

Peltola, H., Kellomäki, S., Väisänen, H., and Ikonen, V.: A mechanisticmodel for assessing the risk of wind and snow damage to single trees and stands of scots pine, norway spruce, and birch, Can. J. Forest Res., 29, 647-661, 1999.

Reardon, B. A., Pederson, G. T., Caruso, C. J., and Fagre, D. B.: Spatial Reconstructions and Comparisons of Historic Snow Avalanche Frequency and Extent Using Tree Rings in Glacier National Park, Montana, U.S.A., Arct. Antarct. Alp. Res., 40, 148-160, 2008.

Schläppy, R., Eckert, N., Jomelli, C., Stoffel, M., Grancher, D., Brunstein, D., Naaim, M., and Deschatres, M.: Validation of extreme snow avalanches and related return periods derived from a statistical-dynamical model using tree-ring techniques, Cold Reg. Sci. Technol., 99, 12-26, 2004.

Sukhanov, G.: The mechanism of avalanche air blast formation as derived from field measurements, Data Glaciol. Stud., 44, 94-98, 1982.

Sukhanov, G. and Kholobaeva, P.: Vriability of avalanche air blast in time and space, Data Glaciol. Stud., 44, 98-105, 1982. 